\title{
Infection prevention and control measures in audiology practice within public healthcare facilities in KwaZulu-Natal province, South Africa
}

\begin{tabular}{|c|c|}
\hline \multicolumn{2}{|c|}{$\begin{array}{l}\text { Authors: } \\
\text { Nasim B. Khan }{ }^{1} \\
\text { Chenay R. Charles }^{1} \\
\text { Naedene Naidoo }^{1} \\
\text { Amanda Nokubonga }^{1} \text { (D) } \\
\text { Ndabenhle A. Mkhwanazi }^{1} \\
\text { Hella M.T.E. Moustache }\end{array}$} \\
\hline \multicolumn{2}{|c|}{$\begin{array}{l}\text { Affiliations: } \\
{ }^{1} \text { Discipline of Audiology, } \\
\text { School of Health Sciences, } \\
\text { University of KwaZulu-Natal, } \\
\text { Durban, South Africa }\end{array}$} \\
\hline \multicolumn{2}{|c|}{$\begin{array}{l}\text { Corresponding author: } \\
\text { Nasim Khan, } \\
\text { khanna@ukzn.ac.za }\end{array}$} \\
\hline \multicolumn{2}{|c|}{$\begin{array}{l}\text { Dates: } \\
\text { Received: } 09 \text { Apr. } 2019 \\
\text { Accepted: } 08 \text { Oct. } 2019 \\
\text { Published: } 02 \text { Dec. } 2019\end{array}$} \\
\hline \multicolumn{2}{|c|}{$\begin{array}{l}\text { How to cite this article: } \\
\text { Khan, N.B., Charles, C.R., } \\
\text { Naidoo, N., Nokubonga, A., } \\
\text { Mkhwanazi, N.A., \& } \\
\text { Moustache, H.M.T.E. (2019). } \\
\text { Infection prevention and } \\
\text { control measures in } \\
\text { audiology practice within } \\
\text { public healthcare facilities in } \\
\text { KwaZulu-Natal province, } \\
\text { South Africa. South African } \\
\text { Journal of Communication } \\
\text { Disorders, 66(1), a636. } \\
\text { https://doi.org/10.4102/ } \\
\text { sajcd.v66i1.636 }\end{array}$} \\
\hline \multicolumn{2}{|c|}{$\begin{array}{l}\text { Copyright: } \\
\text { (C) 2019. The Authors. } \\
\text { Licensee: AOSIS. This } \\
\text { is licensed under the } \\
\text { Creative Commons } \\
\text { Attribution License. }\end{array}$} \\
\hline \multicolumn{2}{|l|}{ Read online: } \\
\hline 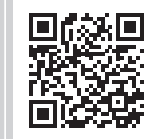 & $\begin{array}{l}\text { Scan this QR } \\
\text { code with your } \\
\text { smart phone or } \\
\text { mobile device } \\
\text { to read online. }\end{array}$ \\
\hline
\end{tabular}

Background: Audiologists have a clinical and ethical responsibility to create a working environment, designed to reduce the potential for cross-contamination or transmission of infections.

Objectives: To describe the infection prevention and control (IPC) measures utilised and the opinions of audiologists and speech therapists, and audiologists (A/STAs) towards IPC in public healthcare facilities in KwaZulu-Natal province, South Africa.

Method: A quantitative, descriptive survey was utilised and entailed completing an online questionnaire. The Cronbach's alpha (0.82) indicated good internal consistency of the tool. Forty-nine A/STAs from 29 public healthcare facilities responded.

Results: Most participants (82\%) followed a generic Department of Health policy on IPC, while $67 \%$ alluded to a discipline-specific policy. Participants had received training in infection control but indicated that further instruction was required for audiology-specific infection control procedures. Only 57\% indicated that they 'sometimes' wore gloves with every patient during direct clinical contact. An association between the healthcare facility level and the wearing of gloves was found to be statistically significant $(p=0.025)$. Participants at regional and tertiary levels contended that gloves should be worn during most procedures versus those at district levels of care. While $96 \%$ washed their hands after each patient, only $76 \%$ washed their hands before each patient. Twenty-nine per cent indicated that they only 'sometimes' wore masks when in contact with patients with communicable diseases. Approximately one-third disinfected touch surfaces and toys, based on the clinician's discretion. The majority (86\%) of participants, however, always followed the correct protocol for medical waste disposal. Despite training and the availability of policies, some practitioners displayed poor IPC practices in terms of universal precautions, personal protective equipment, handwashing and sterilisation.

Conclusion: Further education, training and awareness related to appropriate IPC measures are recommended for audiologists. It is envisaged that this will lead to more effective IPC measures in audiology practice thereby reducing the risk of infection transmission.

Keywords: infection prevention; infection control; handwashing; universal precautions; personal protective equipment; waste management.

\section{Introduction}

Infection prevention and control (IPC) measures are defined as eliminating or minimising the potential spread of disease by consciously managing the clinical environment (Bankaitis, 2005a). According to the World Health Organization (WHO), infectious diseases are the second leading cause of death, after heart diseases, worldwide (WHO, 2008). Nosocomial infections or hospital acquired infections (HAIs) can result in prolonged hospital stays, increased mortality and morbidity, and an increased financial burden for the health sector (Mahomed, Mahomed, Sturm, Knight, \& Moodley, 2017). Despite the limited literature and lack of intervention and impact studies, the clinical environment in patient care has widely been recognised as crucial for patient safety through proper IPC measures (Peters et al., 2018).

The scope of audiology has expanded over the years to include vestibular and balance testing, intraoperative monitoring and cerumen management; therefore, infection control is an area that has become increasingly important (Burco, 2007). Audiologists provide rehabilitative and diagnostic services that are required by patients who differ in various factors, including underlying disease, age and socio-economic status (Ehlert \& Naude, 2014). Healthy patients have a general 
resistance to infection, whereas neonatal intensive care unit (NICU) infants and the elderly, who also require audiology services, have lower resistance and may be more susceptible to infections. Immunocompromised individuals with underlying diseases, that is, tuberculosis (TB), human immunodeficiency virus (HIV) and acquired immunodeficiency syndrome (AIDS), may present with a hearing loss because of the nature of the virus and exposure to antiretroviral treatment (Burco, 2007).

Audiologists in clinical practice have a great degree of indirect and direct contact with patients during procedures to assess the auditory system (Health Professionals Council of South Africa [HPCSA], 2012). Although the risk of HIV and AIDS transmission is remote, by conducting various procedures, including but not limited to, vestibular testing and intraoperative monitoring, audiologists may be exposed to bodily fluids and blood, thus increasing the risk of infection (Burco, 2007). The majority of HAIs occur via the transmission of pathogens, especially by healthcare practitioners (HCPs) who do not wash their hands after treating a patient or properly complying with hospital IPC measures (Adegboye, Zakari, Ahmed, \& Olufemi, 2018). The hands of HCPs are thus responsible for up to $50 \%-70 \%$ of all HAIs and are the main vectors for spreading diseases (Peters et al., 2018).

According to the $\mathrm{WHO}$, there were approximately 558000 cases of multidrug-resistant (MDR) TB worldwide in 2017 (WHO, 2018). South Africa has one of the world's highest TB epidemics, which is driven by HIV (Claassens et al., 2013; Peters et al., 2018) and the second highest number of identified MDR TB cases after India (Churchyard et al., 2014). Its treatment includes a group of antibiotics termed aminoglycosides, which are ototoxic and target the cochlea vestibular system. Managing individuals with TB requires the inclusion of the appropriate HCPs, including audiologists, who are essential in monitoring the effects of ototoxic medication on hearing (Khoza-Shangase, 2013). A South African study by Khoza-Shangase and Van Rie (2017) conducted with 96 participants from an HIV and AIDS research unit indicated that, of those diagnosed with HIV and AIDS, 14\% reported co-occurring vestibular symptoms and $69 \%$ reported experiencing co-occurring audiological symptoms. Therefore, audiologists and speech therapists, and audiologists (A/STAs) in a South African context have numerous contacts with patients with communicable diseases and should implement effective IPC practices when in contact with all patients (Khoza-Shangase \& Van Rie, 2017), thus embracing universal precautions.

In a study by Alp, Leblebicioglu, Doganay and Voss (2011) regarding infection control practices in countries with limited resources, a comparison was made between two countries, Turkey and the Netherlands, of different socio-economic statuses. The results indicated that the attitude of HCPs in hospitals that were not well equipped affected the infection rate. Alp et al.'s study findings correlated with Peters et al.'s (2018) study that low salaries, inadequate facilities and limited infrastructure caused HCPs to lose enthusiasm for their profession and thus do the bare minimum. Therefore, this may have resulted in the incorrect implementation of IPC measures (Alp et al., 2011; Sahiledengle, Gebresilassie, Getahun, \& Hiko, 2018).

The HPCSA recommends that general universal infection control measures need to be followed by all HCPs, regarding hygiene and cleanliness (HPCSA, 2002). These routine precautions include: (1) washing hands before and after every patient; (2) wearing gloves when conducting an oral peripheral examination; (3) washing, wiping or soaking any non-disposable equipment, including toys, with sterilising solution, whenever used; and (4) the correct disposal of waste in appropriate waste disposal bags directly after use (HPCSA, 2002). This is reiterated by the South African Speech-Language Hearing Association (SASLHA) (2011) that indicates that hand hygiene, handwashing, the use of personal protective equipment (PPE) and cleaning or sterilising and disinfecting are essential procedures in audiology-specific infection control for minimising the spread of infectious diseases (SASLHA, 2011). Similarities were noted in Ehlert and Naude's (2014) and Burco's (2007) studies, which indicated that $84 \%$ of respondents from Burco's study and $82 \%$ from Ehlert and Naude's study recognised the significance of handwashing. Results from a study by Archanalakshmi, Stanly and Paul (2015) revealed that when individuals worked for $30 \mathrm{~h}-40 \mathrm{~h}$, only $62 \%$ indicated that they would wash hands. However, only $22 \%$ of individuals who worked for $40 \mathrm{~h}-50 \mathrm{~h}$ would wash hands. This indicates that when HCPs work for longer hours, the chances of washing hands decrease (Archanalakshmi et al., 2015). Gloves can be used to reduce hand contamination from blood and other infectious agents, but cannot prevent injury from sharp objects or instruments. The risk of cross-contamination increases if gloves are not changed between patients or if they are contaminated with bodily fluids. Their use is not a substitute for handwashing, therefore necessitating that hands be washed after the removal of gloves (WHO, 2001, 2004).

According to the Canadian Association of Speech, Language Pathologists and Audiologists (CASLPA, 2010), audiologists use and reuse clinical equipment across a wide range of patients. These consist of otoscope speculae, probes and headphones, which can be reused, but should be cleaned, disinfected and/or sterilised after each patient. Cleaning eliminates gross contamination but does not remove germs from the objects or surfaces and should therefore be a precursor to disinfection and sterilisation (CASLPA, 2010). Results from Ehlert and Naude's study indicated that $60 \%$ of respondents sterilised their audiological equipment after seeing each patient. Less than $50 \%$ of respondents disinfected toys and touch surfaces, compared to Burco's study where approximately $40 \%$ disinfected, and would only do so if there was visible contamination, with the latter disinfection dictated by the audiologists' discretion (Burco, 2007; Ehlert \& Naude, 2014). Toys that are situated in the waiting area should also be disinfected daily, as children could insert them 
into their mouths, resulting in saliva on the toy, which is a source of bacteria (Burco, 2007; Ehlert \& Naude, 2014). Thus, the significance of infection control regarding toys, audiological equipment and touch surfaces before and after patients should be emphasised, as this reduces the transmission of diseases and cross-contamination of microorganisms. Correct waste disposal is a strategy used to prevent and minimise infections among HCPs and community members, which is an essential infection control intervention (Haifete, Justus, \& Iita, 2016). If medical waste is not disposed of correctly, it can become an agent to increase the spread of diseases such as HIV and AIDS, hepatitis B and other communicable diseases, which may result in HCPs, patients and even the community being affected (Haifete et al., 2016).

Limited studies have been conducted in South Africa in this area, despite the emerging burden of communicable or infectious diseases and the expanding scope of practice in audiology. In addition, audiologists working within the public sector face various resource limitations, which could have an impact on the IPC measures available. Information obtained from the study will be used to make contextually appropriate recommendations for infection control measures and practices.

\section{Materials and methods}

The main aim of the study was to determine the IPC measures utilised by A/STAs in public healthcare facilities in KwaZuluNatal (KZN). A secondary aim was to describe the opinions of A/STAs towards IPC in public healthcare facilities in KZN province, South Africa. The objectives of the study were to describe the IPC policies used, to describe the opinions of A/STAs regarding the training received and training needed, to describe the A/STAs' handwashing practices, to determine the personal protective measures available and used by A/STAs for IPC and to determine the opinions of A/STAs regarding equipment management and waste disposal in public healthcare facilities in KZN, South Africa.

A quantitative, non-experimental, descriptive survey research design was used to obtain information from the 83 A/STAs conveniently sampled from 39 public healthcare facilities in the 11 districts within KZN during 2017. A pilot study was conducted on 9 of the 83 A/STAs, with the remaining $74 \mathrm{~A} / \mathrm{STAs}$ being the target group for the main study. Responses were obtained from 59\% ( $n=49$ people), this being from 29 out of 39 of the targeted public healthcare facilities. A questionnaire (Appendix 1) was developed from the three studies conducted by Amlani (1999), Burco (2007) and Ehlert and Naude (2014) consisting of five sections (A-E) with 40 questions. The questionnaire included multiplechoice, closed, open-ended and contingency questions (Leedy \& Ormrod, 2015).

The A/STAs were emailed the link to the Google forms survey where an informed consent letter provided information about the research study, assurance of confidentiality and instructions for completing the questionnaire. After 10 working days, the researchers contacted the A/STAs' department at the various healthcare facilities to remind them to complete the questionnaire. One week later, an email reminder via Google forms was sent to the A/STAs' departments, with a total of three reminders being sent to encourage them to complete the questionnaire in an effort to improve the response rate. The participants were given approximately 3 weeks to complete the questionnaire.

Prior to analysis of the data using the Statistical Package for Social Sciences (SPSS Version 24), the researchers coded the results onto a Microsoft Excel spreadsheet for easy analysis. Once all the data were collected, the results were transferred from Excel to SPSS for analysis. Descriptive statistics and inferential statistics (Pearson's chi-square test) were used. Information obtained from the open-ended questions was used to report on the participants' subjective data specifically regarding the implementation of IPC practices within public healthcare facilities in KZN.

To ensure reliability and test the internal consistency of the study, the Cronbach's alpha was utilised, and revealed a score of 0.821 , indicating good internal consistency of the tool (Sirakaya-Turk, Uysal, Hammitt, \& Vaske, 2017). The data collection tool was developed based on the findings of previous studies, and an extensive review of the literature was conducted to ensure its reliability and validity (Amlani, 1999; Burco, 2007; Ehlert \& Naude, 2014). The content validity of the questionnaire was addressed through the pilot study with six qualified A/STAs. They completed the forms online to test the process. In addition, they had to complete a pilot feedback form indicating the ease of administration, whether the questions were ambiguous, or whether the questions needed to be changed in any way to avoid misunderstanding that could lead participants in a particular direction, thereby creating bias. The changes suggested were implemented in the questionnaire prior to the main study.

\section{Ethical considerations}

Ethical approval was obtained from the Humanities and Social Sciences Research Ethics Committee at UKZN (Ethical clearance number: HSS/0377/017U). Once approval had been obtained from the KZN Provincial Department of Health and Health District Managers, the hospital and medical managers were contacted with a request for permission to conduct the study at the healthcare facilities. Anonymity and confidentiality were maintained, as no names were recorded and the data collected were only available to the researchers, supervisor and statistician. Participation in the study was voluntary and the participants were informed that they could withdraw from the study at any time. 


\section{Results \\ Demographic details}

Participant demographics are summarised in Table 1, with most being between the ages of 21-30 years, female, having a bachelor degree, with $<6$ years' experience.

The results are presented according to the key objectives of the study as follows:

To describe the infection prevention and control policies utilised by audiologists and speech therapists, and audiologists

Sixty-three per cent $(n=31)$ of participants had an audiology-specific IPC policy in place and the majority $82 \%(n=40)$ stated that there was a Department of Health (DoH) policy available. Only 25 participants stipulated the type of policy with most 68\% $(n=17)$, utilising the National DoH's IPC policy. Table 2 provides information regarding the participants' IPC policies used.

TABLE 1: Demographic information ( $n=49)$.

\begin{tabular}{|c|c|c|c|}
\hline Category & Sub-category & $n$ & $\%$ \\
\hline \multirow[t]{3}{*}{ Age (years) } & $21-30$ & 38 & 78 \\
\hline & $31-40$ & 9 & 18 \\
\hline & $41-50$ & 2 & 4 \\
\hline \multirow[t]{2}{*}{ Gender } & Male & 7 & 14 \\
\hline & Female & 42 & 86 \\
\hline \multirow[t]{6}{*}{ Years of experience } & $<1$ year & 17 & 35 \\
\hline & $1-5$ years & 20 & 41 \\
\hline & $6-10$ years & 8 & 16 \\
\hline & $11-15$ years & 2 & 4 \\
\hline & $16-20$ years & 1 & 2 \\
\hline & $>20$ years & 1 & 2 \\
\hline \multirow[t]{3}{*}{ Level of education } & Community service & 15 & 31 \\
\hline & Bachelor's degree & 31 & 63 \\
\hline & Master's degree & 3 & 6 \\
\hline \multirow[t]{4}{*}{ Practice setting } & Rural & 21 & 43 \\
\hline & Semi-rural & 9 & 18 \\
\hline & Urban & 17 & 35 \\
\hline & Semi-urban & 2 & 4 \\
\hline \multirow[t]{5}{*}{ Level of healthcare facility } & District hospital & 25 & 51 \\
\hline & Regional hospital & 12 & 25 \\
\hline & Provincial hospital & 7 & 14 \\
\hline & Central hospital & 1 & 2 \\
\hline & Specialised hospital & 4 & 8 \\
\hline
\end{tabular}

TABLE 2: Summary of the infection prevention and control policies used by the participants.

\begin{tabular}{|c|c|c|c|c|}
\hline \multirow[t]{2}{*}{ Section } & \multicolumn{2}{|c|}{ Yes } & \multicolumn{2}{|c|}{ No } \\
\hline & $n$ & $\%$ & $n$ & $\%$ \\
\hline \multicolumn{5}{|l|}{ Availability of policies ( $n=49$ ) } \\
\hline Audiology infection control policy available & 31 & 63 & 18 & 37 \\
\hline Followed a generic (DoH) infection policy & 40 & 82 & 9 & 18 \\
\hline \multicolumn{5}{|l|}{ Type of DOH policy followed $(n=25)$} \\
\hline National DOH's infection control policy & 17 & 68 & - & - \\
\hline Provincial KZN DOH's infection control policy & 2 & 8 & - & - \\
\hline Hospital infection control policy & 6 & 24 & - & - \\
\hline
\end{tabular}

DOH, Department of Health; KZN, KwaZulu-Natal.
To describe the opinions of audiologists and speech therapists, and audiologists regarding the training received and training needed

Only $41 \%(n=20)$ of participants received audiology-specific IPC training, with most rating their training as good or satisfactory. In an open-ended response, participants indicated that they would like more information regarding audiology-specific infection control, sterilisation and disinfection of instruments to be included in infection control training. Participants also mentioned that they would like annual education and training sessions (such as workshops, short courses and literature) regarding audiology-specific infection control and that public healthcare facilities should have improved resources for proper implementation of IPC measures. Table 3 provides information regarding training A/STAs received and additional training needs.

\section{To describe the handwashing practices of audiologists and speech therapists, and audiologists}

All of the participants reported that adequate hand hygiene is an essential part of infection control. The results indicated that $98 \%(n=48)$ had access to alcohol-based hand rub, and 71\% $(n=35)$ had a sink with running water, with the sink being $<50 \mathrm{~m}$ from their consultation area. Participants washed their hands with water and soap (33\%), hibitane solution (33\%) or liquid hand wash (30\%). Table 4 illustrates the handwashing practices followed by participants within their working

TABLE 3: Summary of the training the audiologists and speech therapists, and audiologists had received and additional training needs.

\begin{tabular}{|c|c|c|c|c|}
\hline \multirow[t]{2}{*}{ Section } & \multicolumn{2}{|c|}{ Yes } & \multicolumn{2}{|c|}{ No } \\
\hline & $n$ & $\%$ & $n$ & $\%$ \\
\hline \multicolumn{5}{|c|}{ Necessity for training and training received $(n=49)$} \\
\hline IPC training was necessary & 45 & 92 & 4 & 8 \\
\hline Received audiology-specific training & 20 & 41 & 29 & 59 \\
\hline \multicolumn{5}{|c|}{ Participants' subjective rating of training received $(n=20)$} \\
\hline \multicolumn{5}{|c|}{ Rating } \\
\hline Excellent & 1 & 5 & - & - \\
\hline Good & 7 & 35 & - & - \\
\hline Satisfactory & 8 & 40 & - & - \\
\hline Adequate & 4 & 20 & - & - \\
\hline \multicolumn{5}{|c|}{ Additional training needs (number of responses $=85$ ) } \\
\hline Audiology-specific IPC measures & 22 & 26 & - & - \\
\hline $\begin{array}{l}\text { Sterilisation and disinfection of } \\
\text { instruments }\end{array}$ & 21 & 25 & - & - \\
\hline Personal protective measures & 19 & 22 & - & - \\
\hline Handwashing & 12 & 14 & - & - \\
\hline Waste disposal & 6 & 7 & - & - \\
\hline Advice on ventilation & 5 & 6 & - & - \\
\hline
\end{tabular}

IPC, infection prevention and control.

TABLE 4: Participants' handwashing practices.

\begin{tabular}{lcccccc}
\hline Handwashing practices & \multicolumn{2}{c}{ Yes } & & \multicolumn{2}{c}{ No } \\
\cline { 2 - 3 } \cline { 6 - 7 } & $\boldsymbol{n}$ & $\mathbf{0}$ & & $\boldsymbol{n}$ & $\mathbf{\%}$ \\
\hline Before each patient & 37 & 76 & & 12 & 24 \\
After each patient & 47 & 96 & & 2 & 4 \\
After cerumen management & 43 & 88 & & 6 & 12 \\
After earmould impression taking & 47 & 96 & & 2 & 4 \\
After the use of the toilet & 47 & 96 & & 2 & 4 \\
After contact with bodily fluids & 46 & 94 & & 3 & 6 \\
After removal of gloves & 33 & 67 & & 16 & 33 \\
\hline
\end{tabular}

Source: Authors' own data compilation with some of the handwashing practices adapted from Amlani (1999), Burco (2007) and Ehlert and Naude (2014) 
TABLE 5: Use of gloves during audiological procedures.

\begin{tabular}{|c|c|c|c|c|c|c|}
\hline \multirow[t]{2}{*}{ Procedures } & \multicolumn{2}{|c|}{ Always } & \multicolumn{2}{|c|}{ Sometimes } & \multicolumn{2}{|c|}{ Never } \\
\hline & $n$ & $\%$ & $n$ & $\%$ & $n$ & $\%$ \\
\hline Otoscopy & 38 & 78 & 11 & 22 & - & - \\
\hline Immittance & 38 & 78 & 10 & 20 & 1 & 2 \\
\hline Cerumen management & 44 & 90 & 4 & 8 & 1 & 2 \\
\hline Evoked potential testing & 23 & 47 & 23 & 47 & 3 & 6 \\
\hline Vestibular and balance testing & 23 & 47 & 23 & 47 & 3 & 6 \\
\hline Earmould impression taking & 18 & 36 & 19 & 39 & 12 & 25 \\
\hline Hearing aid fittings & 20 & 41 & 20 & 41 & 9 & 18 \\
\hline Hearing aid modifications & 20 & 41 & 23 & 47 & 6 & 1 \\
\hline
\end{tabular}

Source: Authors' own data compilation with some of the procedures and rating scale adapted from Amlani (1999), Burco (2007) and Ehlert and Naude (2014)

environment. Interestingly, only $76 \%(n=37)$ washed their hands prior to managing patients, while the majority $96 \%$ $(n=47)$ washed their hands after each patient. Only $67 \%$ $(n=33)$ washed their hands after the removal of gloves.

\section{To determine the personal protective measures available and used by the audiologists and speech therapists, and audiologists for infection prevention and control}

Eighty-six per cent $(n=42)$ believed that their workplace had a high exposure to communicable diseases, while only $22 \%$ $(n=11)$ believed that their workplace had adequate ventilation for individuals with communicable diseases such as TB. Seventy-one per cent $(n=35)$ indicated that masks should always be worn with patients with communicable diseases, while 29\% $(n=14)$ felt that this was only necessary sometimes. More than half $(57 \%, n=28)$ reported wearing gloves sometimes with every patient, while $43 \%(n=21)$ always wore them with every patient. An association between the level of the healthcare facility and the wearing of gloves was found to be statistically significant $(p=0.025)$ with more participants at regional and tertiary levels being of the opinion that gloves should be worn during most procedures versus those at district levels of care. Table 5 indicates how often participants wore gloves during various audiological procedures. Participants responded to a three-point Likert scale (with options always, sometimes and never).

\section{To determine the opinions of audiologists and speech therapists, and audiologists regarding equipment management and waste disposal in public healthcare facilities in KwaZulu-Natal, South Africa}

All the participants $(n=49)$ contended that the otoscope specula should be disinfected and/or sterilised on a daily basis, while $94 \%(n=46)$ and $98 \%(n=48)$ indicated that immittance probe tips and headphones should be disinfected and/or sterilised on a daily basis. A few $(14 \%, n=7)$ believed that earmoulds used during hearing aid fittings should not be disinfected and/or sterilised. The majority of participants contended that otoscope specula, immittance probes, otoacoustic emission (OAE) probes, headphones and insert earphones could expose them to infectious diseases, while $32 \%(n=16)$ felt that this was not possible through distraction toys. Only $6 \%(n=3)$ believed that touch surfaces, such as countertops, armchair rests or counselling table surfaces, should be disinfected after each appointment. Only 40\% $(n=$ 19) and $27 \%(n=13)$ believed that touch surfaces and paediatric toys, respectively, should be disinfected as needed, based on the discretion of the clinician. Figure 1 illustrates the frequency

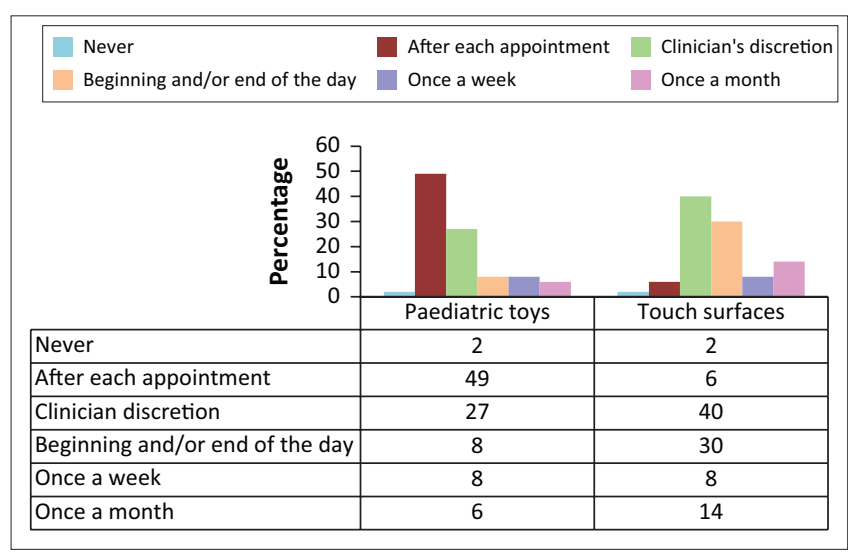

Source: Authors' own data compilation with some variables and rating scale adapted from Ehlert, K., \& Naude, A.M. (2014). Infection prevention and control measures currently applied in South African audiology. South African Journal of Communication Disorders, 61(1), 1-10. https://doi.org/10.4102/sajcd.v61i1.55

FIGURE 1: Frequency of disinfecting paediatric toys and touch surfaces $(n=49)$.

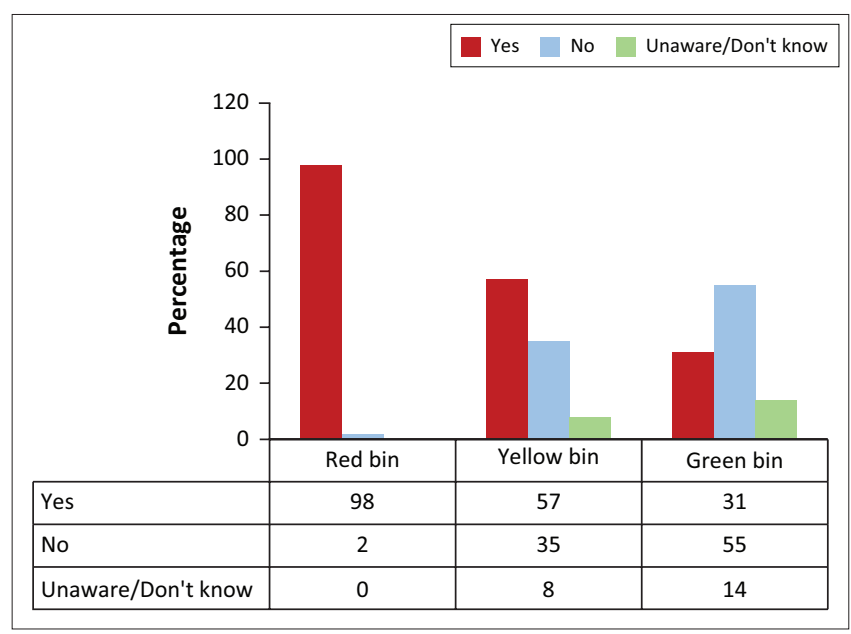

FIGURE 2: Medical waste disposal bins available at participants' workplace $(n=49)$

of participants' responses in relation to the disinfection of paediatric toys and touch surfaces.

All the participants believed that medical waste should not be put in the same bin as general waste, and $80 \%(n=39)$ indicated that hearing aid batteries should be disposed of separately from other waste. The majority $(98 \%, n=48)$ indicated that they had red medical waste disposal bins available (for infectious substances such as gloves and alcohol swabs) and 57\% $(n=28)$ had the yellow medical waste disposal bins available (for sharps such as needles and syringes), while only $31 \%(n=15)$ had the green medical 
waste disposal bins (for pharmaceuticals, i.e. expired medication) at their workplace (see Figure 2).

\section{Discussion}

Implementing effective infection control measures is essential for any HCP, with adherence to IPC guidelines being stipulated by employing bodies, regulatory bodies (HPCSA, 2002) and professional associations, such as SASLHA (SASLHA, 2011). It was encouraging to note that $67 \%$ of the participants had a discipline-specific infection control policy in their workplace, which correlated with results obtained from the study by Burco (2007), who indicated that $61 \%$ of respondents had audiology-specific infection control plans in place. Research findings from Burco's (2007) study indicated that nearly $60 \%$ of respondents received audiology-specific infection control training prior to employment, while results from the current research study indicated a lower percentage. It was of concern that some participants were unaware of discipline-specific policies in their workplace. Results from the current study indicated that only $49 \%$ believed that paediatric toys should be disinfected after each appointment, while $27 \%$ indicated that they would disinfect 'at the clinician's discretion'. This correlated with results from Ehlert and Naude's (2014) study, which indicated that less than half of the respondents disinfected touch surfaces and toys, and would only do so if there was visible contamination. Therefore, participants may have been unwittingly transmitting disease, causing microbes from patient to patient by not adhering to proper infection control guidelines. Education and training for HCPs is essential on a regular basis to increase awareness about infection control policies and guidelines, and it results in improved adherence to these practices and measures, changes negative attitudes and promotes a safer environment (Ojulong, Mitonga, \& Iipinge, 2013; Schellack, Ismail, \& Babarinde, 2016).

Addis Ababa and India are similar to other developing countries, such as South Africa, where there are minimal efforts to prevent and control HAIs (Sahiledengle et al., 2018). Hand hygiene is the most effective, least costly and simplest method of decreasing the incidence of HAIs (Mathur, 2011) but it is not recognised as such or appreciated by healthcare workers (Ojulong et al., 2013). In healthcare, hands are another extremely mobile surface that are frequently contaminated and seldom disinfected (Peters et al., 2018). All of the participants reported that adequate hand hygiene was an essential part of infection control. The most common handwashing method was washing hands with soap and water and using hibitane, with $33 \%$ of participants choosing either method. According to Ehlert and Naude (2014), hand sanitisers are an approved and effective method for hand hygiene, reported to be more effective than washing hands with soap and water. However, according to the WHO's guidelines on hand hygiene in healthcare (WHO, 2006), based on evidence from several studies, antiseptic alcoholbased hand rubs demonstrated maximum efficacy in removing pathogens from the hands of healthcare workers.
These may not be available in all contexts, given costs and cultural beliefs (for example, the Islamic religious beliefs are against the use of alcohol for any purpose). It is thus recommended that currently utilised, commercially available hand rub and liquid soaps meet acceptable standards, as outlined in the guideline for IPC (WHO, 2006).

Almost a quarter of the participants indicated that they did not wash their hands before each patient, which was also a concern raised by Ehlert and Naude (2014); perhaps they believed that they cannot transmit infection to their patients. Approximately one-third of the participants reported not washing hands after removing gloves. Although only $67 \%$ of participants believed that it was necessary to wash hands after cerumen management, $88 \%$ of participants reported that they washed their hands after cerumen management. However, this is still concerning, as cerumen can be considered an infectious substance and may lead to opportunistic infections, such as methicillin-resistant Staphylococcus aureus (MRSA) (Kemp \& Bankaitis, 2000; Patel, Engelbrecht, McDonald, Morris, \& Smythe, 2016).

Universal precautions are the most effective and simple way of preventing infection in healthcare settings (WHO, 2001). These guidelines include using appropriate PPE or prophylactic measures, such as gloves, N-95 masks (respiratory hygiene), cough etiquette, hand hygiene, environmental cleanliness and waste management (Fayaz et al., 2014; WHO, 2001). It was concerning that more than half of the participants only sometimes wore gloves with every patient, as a 2012 South African survey estimated 12.2\% of the population to be living with HIV and AIDS (Shisana et al., 2014). Encouragingly, the majority (78\%) of participants were of the opinion that gloves should be worn during routine procedures, such as otoscopy and immittance. One-third felt that gloves should be worn during earmould impression taking and hearing aid fitting, which correlated with results from the study by Ehlert and Naude (2014). These results are concerning as research by Ahmad et al. (2007) indicated that earmoulds may harbour pathogenic microorganisms that can result in the development of chronic otitis externa such as staphylococci, bacteria and fungi (Ahmad, Etheridge, Farrington, \& Baguley, 2007; Bankaitis, 2005b).

Half the participants contended that hearing aids could not expose them to infectious diseases, these concerning findings being similar to Bankaitis's (2002) study, which reported Staphylococcus bacterium on the surface of hearing aids, this being implicated in HAIs (Bankaitis, 2002). This was supported in a study by Sturgulewski, Bankaitis, Klodd and Haberkamp (2006), where fungi, bacteria and even faecal matter were found on the surface of hearing aids. Thus, hearing aids have been implicated as a source of microbial transmission and should be treated as a vector (Sturgulewski et al., 2006). Results from Bankaitis (2005b) indicate that as alcohol does not kill bacteria or fungi, given the extent of reported microbial growth on hearing aid and earmould surfaces. Audiologists and speech therapists, and 
audiologists should be made aware that the use of PPEs is essential while handling hearing aids and all related accessories, as disinfection may be insufficient (Bankaitis, 2005b). Bankaitis and Kemp (2010) suggest that IPC is not an arbitrary process and should be based on established guidelines and compliance thereof.

It was concerning that almost half the participants $(47 \%)$ indicated that they would only sometimes wear gloves during evoked potentials and vestibular testing; however, it was encouraging that an equal number indicated that they would always wear gloves. It was important to note that about a quarter of the participants from Khoza-Shangase and Van Rie's study (2017) reported that they had diminished hearing sensitivity since being diagnosed with HIV and AIDS. This is further supported by the literature from Heinze, Swanepoel and Hofmeyer (2011), in which reports of auditory and vestibular manifestations were identified in patients with HIV and AIDS (Heinze et al., 2011), necessitating audiological services. Results from the Khoza-Shangase and Van Rie study (2017) also found that patients with HIV and AIDS are prone to middle ear infections and otorrhoea, which are symptoms indicative of middle ear pathology, also present with co-occurring vestibular and audiologic symptoms. As the A/STAs' scope of practice has increased to include vestibular testing, A/STAs need to be cognisant that some patients who have possible ear infections are likely to be immunocompromised, and that proper use of gloves and other PPEs need to be used during all procedures to prevent the spread of opportunistic infections (Khoza-Shangase \& Van Rie, 2017). Many opportunistic infections can be prevented through correct implementation and compliance to evidence-based IPC measures. Although researchers have highlighted the importance of universal precautions, few studies have examined audiologists' infection control practices, despite the many challenges these HCPs face in resource-limited settings (Russell et al., 2018).

The results from the current study indicated that $25 \%$ of the participants believed that masks should only be worn when they are in contact with an individual with a communicable disease. Sahiledengle et al.'s (2018) study revealed that more than half $(57.9 \%)$ of the HCPs wore masks when in contact with a patient suspected of, or confirmed with having $\mathrm{TB}$, with the results being slightly higher than a study previously conducted in the same city, which revealed that only $50.2 \%$ wore masks. However, microorganisms that cause communicable diseases cannot be seen with the naked eye and HCPs would be unaware of the patients' medical diagnosis (Claassens et al., 2013), leaving them at risk for acquiring a communicable disease. The majority of the participants $(86 \%)$ reported that their workplace had a high exposure to communicable diseases, which has nearly doubled from Burco's (2007) and Amlani's (1999) studies being $48 \%$ and $20 \%$, respectively. Seventy-eight per cent of the participants reported that their workplace did not have adequate ventilation, this being important for audiologists whose patients present with TB for ototoxic monitoring (Claassens et al., 2013).
Encouragingly, results from the current research study indicated that all participants believed that otoscope speculae should be sterilised on a daily basis, which is an improvement from Burco's (2007) study, where $42 \%$ of respondents indicated that they sterilised and/or disinfected otoscope. Research indicates that the practices of sterilisation and disinfection of audiological equipment have steadily improved over the years. In the current study, the participants did not believe that hearing aids or acrylic moulds could expose them or their patients to infectious disease, warranting further education and training (SASLHA, 2011). According to Bankaitis and Kemp (2002), whether attempting to obtain an earmould impression, using the earmould when doing a hearing aid fitting or removing the earmoulds from the patients ear (e.g. making adjustments to the hearing aid), it must be cleaned and handled with gloves. The earmould makes contact with the patient's ear canal and can be contaminated with substances lining the ear canal with blood, cerumen or ear infection. It is therefore important to use a disinfectant spray on the hearing aid and earmould to minimise the risk of cross-infection. Implementing effective IPC practices in the audiological environment also provides an opportunity for A/STAs to educate their patients about proper hearing instrument hygiene, care and maintenance (Bankaitis, 2002).

Equipment and surfaces that may be frequently touched are thought to provide the greatest risk for patients (Dancer, 2009). In Burco's study, one-third of the participants did not believe that distraction toys could expose them to infectious disease (Burco, 2007). The results regarding disinfecting at the clinician's discretion correlated with Burco's (2007) findings, which indicated that $40 \%$ would only disinfect when there was visible contamination. Paediatric toys and touch surfaces should be sterilised according to professional infection control guidelines and after each patient appointment to prevent cross-contamination (Dancer, 2009).

Research regarding audiology-specific waste disposal methods is minimal, and according to universal precautions and infection control guidelines, infectious waste should be disposed of appropriately (SASLHA, 2011). It was encouraging to note that all the participants believed that medical and other waste should be disposed of separately, as medical waste can cause the possible spread of disease if it is not disposed of properly. Fourteen per cent of the participants believed they should only 'sometimes' follow the correct medical waste disposal methods, which may have been because of their not having the correct medical waste disposal bins available. This correlated with results from the current study, which indicated that $35 \%$ of the participants did not have the yellow and 55\% did not have the green medical waste disposal bins in their workplace.

\section{Conclusion}

The study aimed to determine the IPC measures and opinions of A/STAs in public healthcare facilities in the KZN province, South Africa. The self-reported findings suggest variable 
practices and mixed opinions about IPC practices. Despite training and the availability of policies, some participants displayed poor adherence to standard IPC practices, while others indicated the non-availability of policies and/or discipline-specific training. This suggests that audiology clinics need to be equipped with adequate discipline-specific policies, and that A/STAs be trained on IPC issues relevant to their practice. Hand hygiene is a cost-effective intervention that should be practiced before and after patients, even if gloves were worn. Poor compliance to IPC measures may stem from a deficit in the knowledge and/or attitudes, including perceived barriers such as lack of time, patient and HCP discomfort, lack of resources (PPE) and the sense that protective equipment interferes with work performance. An effective infection control programme depends largely on the personnel responsible for its implementation, there has to be a mechanism in place for monitoring. Information, education, training, guidelines and effective practices are essential to break the cycle of inadequate infection control. Ultimately, it is the audiologist's responsibility to ensure that effective IPC measures are routinely adhered to in clinical practice.

\section{Limitations and recommendations}

A small sample size limited the generalisability of the study to HCPs, as it was only conducted in public healthcare facilities in KZN. Information bias may have occurred as participants may not have taken time to consider each question, but may rather have completed the questionnaires quickly. The compliance with IPC was based on reported practices of audiologists and not those directly observed by the researchers, which could have resulted in them providing answers that they thought more appropriate, thus introducing social desirability bias. The researchers could have probed more about the barriers to IPC practices that would have been useful when suggesting further clinical and research implications. Increasing the awareness of the importance of IPC within healthcare facilities will help motivate HCPs to implement adequate measures throughout their clinical practice and ensure compliance. Healthcare practitioners could also counsel their patients about the proper cleaning and disinfecting of their hearing instruments. Future research could venture into a more in-depth investigation and consideration of the real environment of audiological practice in public hospitals for more meaningful recommendations to be made. The effectiveness of IPC measures in audiology needs further investigation. The profession needs to advocate for IPC resources to decrease the risk of infections and crosscontamination in healthcare facilities.

\section{Acknowledgements}

The authors would like to thank the participants of the study for their contributions.

\section{Competing interests}

The authors declare that there is no conflict of interest regarding the publication of this article.

\section{Authors' contributions}

N.B.K., C.R.C. and N.N. contributed equally to the write-up of the article. C.R.C., A.N., N.A.M., H.M.T.E.M. and N.N. contributed to the undergraduate research proposal development, data collection and research project. N.B.K. did the supervision.

\section{Funding information}

This research received no specific grant from any funding agency in the public, commercial or not-for-profit sectors.

\section{Data availability statement}

Data sharing is not applicable to this article as no new data were created or analysed in this study.

\section{Disclaimer}

The views and opinions expressed in this article are those of the authors and do not necessarily reflect the official policy or position of any affiliated agency of the authors.

\section{References}

Adegboye, M.B., Zakari, S., Ahmed, B.A., \& Olufem, G.H. (2018). Knowledge, awareness and practice of infection control by health care workers in the intensive care units of a tertiary hospital in Nigeria. African Health Sciences, 18(1), 72-78. https://doi.org/10.4314/ahs.v18i1.11

Ahmad, N., Etheridge, C., Farrington, M., \& Baguley, D.M. (2007). Prospective study of the microbiological flora of hearing aid moulds and the efficacy of current cleaning techniques. The Journal of Laryngology and Otology, 121(2), 110-113. https://doi.org/10.1017/S0022215106002222

Alp, E., Leblebicioglu, H., Doganay, M., \& Voss, A. (2011). Infection control practice in countries with limited resources. Annals of Clinical Microbiology and Antimicrobials, 10(1), 1-4. https://doi.org/10.1186/1476-0711-10-36

Amlani, A.M. (1999). Current trends and future needs for practices in audiologic infection control. Journal of the American Academy Audiolology, 10(3), 151-159.

Archanalakshmi, P.A., Stanly, M., \& Paul, C.M. (2015). Adoption of hand hygiene practices among health care providers. International Journal of Research in Medical Sciences, 3(10), 2807-2809. https://doi.org/10.18203/2320-6012. ijrms20150686

Bankaitis, A.U. (2002). What's growing on your patients' hearing aids? A study gives you an idea. The Hearing Journal, 55(6), 48-54. https://doi.org/10.1097/01. HJ.0000293278.53653.ac

Bankaitis, A.U. (2005a). Infection control in the audiology clinic: Frequently asked questions. Audiology Today, 17(5), 17-19.

Bankaitis, A.U. (2005b). Hearing aids: Lick 'em and stick 'em?: Sticking hearing aids in the mouth is not a good idea! Audiology Today, 16(6), 12-13.

Bankaitis, A.U., \& Kemp, R.J. (2002). Hearing aid related infection control. In M. Valente (Ed.), Strategies for selecting and verifying hearing aid fittings (2nd edn., pp. 369-383). New York: Thieme Publishing Group.

Bankaitis, A.U., \& Kemp, R.J. (2010). ABC's of infection control. The Hearing Journal, July-August-September, 6-9.

Burco, A. (2007). Current infection control trends in audiology. Program in Audiology and Communication Sciences. Washington University School of Medicine, Washington, DC. Paper 287. Retrieved from http://digitalcommons.wustl.edu/ pacs_capstones/287.

CASLPA. (2010). Infection prevention control guidelines in audiology. Canadian Association of Speech-Language Pathologists and Audiologists. Retrieved from http://www.cas/po.com/sites/default/uploads/files/GU_EN_Infection_Prevention_ Control_Guidelines_Audiology.pdf.

Churchyard, G.J., Hesseling, A.C., Mametja, L.D., Mvusi, L., Ndjeka, N., Reid A., ... Pillay, Y. (2014). Tuberculosis control in South Africa: Successes, challenges and recommendations. South African Medical Journal, 104(3 [Suppl 1]), 244-248. https://doi.org/10.7196/SAMJ.7689

Claassens, M.M., Schalkwyk, C.V., Toit, E.D., Roest, E., Lombard, C.J., Enarson, D.A., ... Borgdorff, M.W. (2013). Tuberculosis in healthcare workers and infection control measures at primary healthcare facilities in South Africa. PLOS ONE, 8(10), 1-8. https://doi.org/10.1371/journal.pone.0076272

Dancer, S.J. (2009). The role of environmental cleaning in the control of hospitalacquired infection. Journal of Hospital Infection, 73, 378-385. https://doi. org/10.1016/j.jhin.2009.03.030 
Ehlert, K., \& Naude, A.M. (2014). Infection prevention and control measures currently applied in South African audiology. South African Journal of Communication Disorders, 61(1), 1-10. https://doi.org/10.4102/sajcd.v61i1.55

Fayaz, S.H., Higuchi, M., Hirosawa, T., Sarker, M.A.B., Djabbarova, Z., \& Hamajima, N. (2014). Knowledge and practice of universal precautions among health care workers in four nationals hospitals in Kabul, Afghanistan. Journal of Infection in Developing Countries, 4(8), 535-542. https://doi.org/10.3855/ jidc. 4143

Haifete, A.N., Justus, A.H., \& lita, H. (2016). Knowledge, attitude and practice of healthcare workers on waste segregation at two public training hospitals. European Journal of Pharmaceutical and Medical Research, 3(5) 674-689.

Heinze, B., Swanepoel, D.W., \& Hofmeyr, L.M. (2011). Systematic review of vestibular disorders related to human immunodeficiency virus and acquired immunodeficiency syndrome. Journal of Laryngology and Otology, 125(9), 881-890. https://doi.org/10.1017/S0022215111001423

Health Professionals Council of South Africa (HPCSA). (2002). Standards of practice in audiology (pp. 1-5). Pretoria: The Health Professions Council of South Africa.

Health Professionals Council of South Africa (HPCSA). (2012). Health Professions Act 56 of 1974: Regulations defining the scope of the profession of Audiology. Pretoria: Government Gazette.

Kemp, R.J., \& Bankaitis, A. (2000). Infection control for audiologist. In H. Dunn R. Roeser, \& M. Valente (Eds.), Handbook of audiology: Practice management. New York: Thieme Publishing.

Khoza-Shangase, K. (2013). Ototoxicity in tuberculosis treatment in South Africa: Exploring the current status. African Journal of Pharmacy and Pharmacology, 7(30), 2140-2145. https://doi.org/10.1080/23120053.2016.1216816

Khoza-Shangase, K., \& Van Rie, K.J. (2017). Pathological vestibular symptoms presenting in a group of adults with HIV/AIDS in Johannesburg, South Africa. Southern African Journal of Infectious Diseases, 32(2), 43-53. https://doi.org/10. 1080/23120053.2016.1216816

Leedy, P.D., \& Ormrod, J.E. (2015). Practical research: Planning and design (11th edn.). Edinburgh Gate: Pearson Education, Inc.

Mahomed, S., Mahomed, O., Sturm, A.W., Knight, S., \& Moodley, P. (2017). Challenges with surveillance of healthcare-associated infections in intensive care units in
South Africa. Hindawi: Critical Care Research and Practice, 2017(7296317), 1-8. South Africa. Hindawi: Critical Care Resed
https://doi.org/10.1155/2017/7296317

Mathur, P. (2011). Hand hygiene: Back to the basics of infection control. Indian Journal of Medical Research, 134(5) 611-620. https://doi.org/10.4103/0971 5916.90985

Ojulong, J., Mitonga, K.H., \& lipinge, S.N. (2013). Knowledge and attitudes of infection prevention and control among health sciences students at University of Namibia. African Health Sciences, 13(4), 1071-1078. https://doi. org/10.4314/ahs.v13i4.30
Patel, B., Engelbrecht, H., McDonald, H., Morris, V., \& Smythe, W. (2016). A multifaceted hospital-wide intervention increases hand hygiene compliance. South African Medical Journal, 106(4), 335-341. https://doi.org/10.7196/SAMJ.2016.v106i4.10671

Peters, A., Otter, J., Moldovan, A., Parneix, P., Voss, A., \& Pittet, D. (2018). Keeping hospitals clean and safe without breaking the bank; summary of the Healthcare Cleaning Forum. Antimicrobial Resistance and Infection Control, 7(132), 1-12. https://doi.org/10.1186/s13756-018-0420-3

Pittet, D., Allegranzi, B., Storr, J., Nejad, S.B., Dziekan, G., Leotsakos, A., \& Donaldson, L. (2008). Infection control as a major World Health Organization priority for developing countries. Journal of Hospital Infection, 68(4), 285-292. https://doi. org/10.1016/j.jhin.2007.12.013

Russell, D., Dowding, D.W., McDonald, M.V., Adams, V., Rosati, R.J., Larson, E.L., Shang, J. (2018). Factors for compliance with infection control practices in home healthcare: Findings from a survey of nurses' knowledge and attitudes toward infection control. American Journal of Infection Control, 46(11), 1211-1217. https://doi.org/10.1016/j.ajic.2018.05.005

Sahiledengle, B., Gebresilassie, A., Getahun, T., \& Hiko, D. (2018). Infection prevention practices and associated factors among healthcare workers in governmental healthcare facilities in Addis Ababa. Ethiopian Journal of Health Science, 28(2), 177-186. https://doi.org/10.4314/ejhs.v28i2.9

Schellack, N., Ismail, H., \& Babarinde, O. (2016). Revisiting the principles of infection control. South African Pharmceutical Journal, 83(6), 33-38.

Shisana, O., Rehle, T., Simbayi, L.C., Zuma, K., Jooste, S., Zungu, N., et al., (2014). South African national HIV prevalence, incidence and behaviour survey, 2012. Cape Town: Human Sciences Research Council.

Sirakaya-Turk, E., Uysal, M., Hammitt, W.E., Vaske, J. (2017). Research methods for leisure, recreation and tourism (2nd edn.). Wallingford: CAB International.

South African Speech Language Hearing Association (SASLHA). (2011). Guidelines: Infection control: Guidelines for speech-language therapists and audiologists regarding infection control. Retrieved from http://www.saslha.co.za.

Sturgulewski, S.K., Bankaitis, A.U., Klodd, D.A., \& Haberkamp, T. (2006). What's still growing on your patients' hearing aids? The Hearing Journal, 59(9), 45-48. https://doi.org/10.1097/01.HJ.0000285827.98823.87

WHO. (2001). Infections and infectious diseases: A manual for nurses and midwives in the WHO European Region. UN City: Marmorvej World Health Organization.

WHO. (2004). Practical guidelines for infection control in health care facilities. New Delhi: WPRO Regional Publication.

WHO. (2006). Guidelines on hand hygiene in health care (advanced draft). Global Patient Safety Challenge 2005-2006: 'Clean care is safer care'. Retrieved from https://www.who.int/patientsafety/information_centre/Last_April_versionHH_ Guidelines\%5B3\%5D.pdf

WHO. (2008). The global burden of disease: 2004 update. Retrieved from https://www. who.int/healthinfo/global_burden_disease/GBD_report_2004update_full.pdf

WHO. (2018). Global tuberculosis report 2018. Retrieved from https://www.who.int/ tb/publications/global_report/en/.France 


\section{Appendix 1}

\section{Questionnaire}

\section{Section A: Demographical information}

(Please circle or tick the option(s) that fit best)

\begin{tabular}{|c|c|c|c|c|c|c|}
\hline \multicolumn{7}{|c|}{ Location: KwaZulu-Natal } \\
\hline 1. Age (years) & $21-30$ & $31-40$ & \multicolumn{2}{|c|}{$41-50$} & $51-60$ & $60+$ \\
\hline 2. Gender & \multicolumn{3}{|l|}{ Male } & \multicolumn{3}{|l|}{ Female } \\
\hline 3. Years in practice & $<1$ year & $1-5$ years & $6-10$ years & $11-15$ years & $16-20$ years & $>20$ years \\
\hline 4. Level of education & Community service & \multicolumn{2}{|c|}{ Bachelor's degree } & Master's degree & \multicolumn{2}{|c|}{ Doctoral } \\
\hline
\end{tabular}

\begin{tabular}{|l|l|}
\hline 5. In what setting do you practice? & \\
\hline Rural & \\
\hline Semi-rural & \\
\hline Urban & \\
\hline Semi-urban & \\
\hline
\end{tabular}

\begin{tabular}{|l|l|}
\hline 6. What is the level of the healthcare facility that you currently work at? \\
\hline District hospital (level 1) & \\
\hline Regional hospital (level 2) & \\
\hline Provincial tertiary hospital (level 3) & \\
\hline Central hospital (level 4) & Specialised hospital \\
\hline
\end{tabular}

\begin{tabular}{|l|l|}
\hline 7. Which population do you provide services to at your current workplace? \\
\hline Only adolescents or adults & \\
\hline Majority adolescents or adults & \\
\hline Fairly balanced number of adolescents or adults $(50 \%)$ and paediatrics $(50 \%)$ & \\
\hline Majority paediatrics & \\
\hline Only paediatrics & \\
\hline
\end{tabular}

\begin{tabular}{|l|l|l|l|}
\hline 8. Please list the top five populations which you provide services to in your current workplace (e.g. TB adults, CP children). \\
\hline Q8 a) & Children: & Q8 b) & Adolescents or adults: \\
\hline & & & \\
\hline & & & \\
\hline & & & \\
\hline & & & \\
\hline & & & \\
\hline
\end{tabular}

\begin{tabular}{|l|l|l|}
\hline \multicolumn{3}{|l|}{ In general, which services do you provide to patients? (please tick the option[s] that apply) } \\
\hline Q9 a) & Otoscopy & \\
\hline Q9 b) & Immittance audiometry & \\
\hline Q9 c) & Pure tone audiometry & \\
\hline Q9 d) & Otoacoustic emissions & \\
\hline Q9 e) & Auditory brainstem response & \\
\hline Q9 f) & Auditory steady-state response & \\
\hline Q9 g) & Electronystagmography (ENG) or videonystagmography (VNG) (vestibular and balance testing) \\
\hline Q9 h) & Hearing aid fitting and orientation & \\
\hline Q9 i) & Central auditory processing & \\
\hline Q9 j) & Cerumen management & \\
\hline Q9 k) & Aural rehabilitation & \\
\hline Q9 I) & Other (please specify) & \\
\hline
\end{tabular}




\section{Section B: Infection prevention and control policies and training}

\begin{tabular}{|l|l|}
\hline 10. Do you follow a specific infection control policy (i.e. National Infection Control Policy) at your workplace? \\
\hline Yes & \\
\hline No & \\
\hline Unaware or don't know & \\
\hline
\end{tabular}
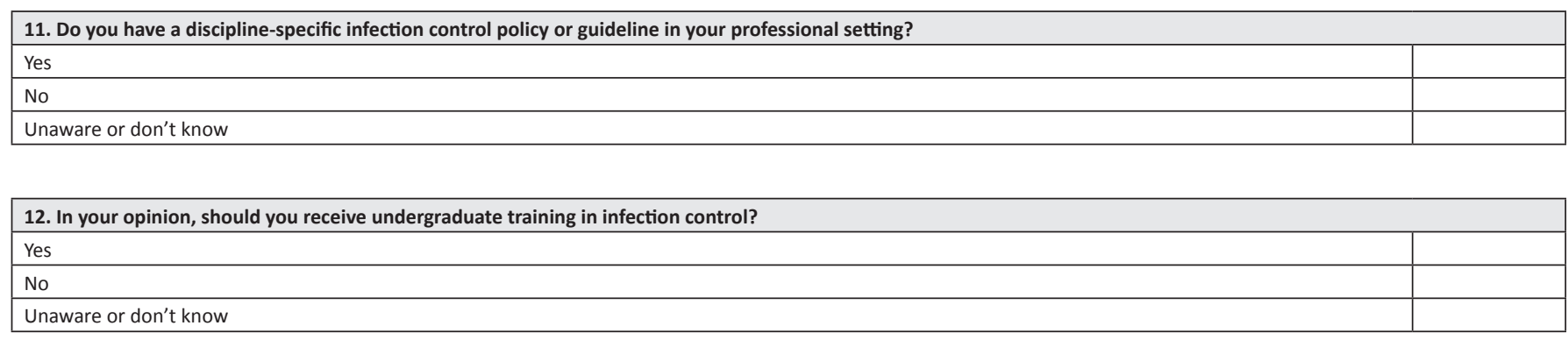

\begin{tabular}{|l|l|}
\hline 13. Have you received any training on audiology-specific infection control in your workplace? \\
\hline Yes & \\
\hline No & \\
\hline Unaware or don't know & \\
\hline
\end{tabular}

If you answered yes to the above question, please answer the question below.
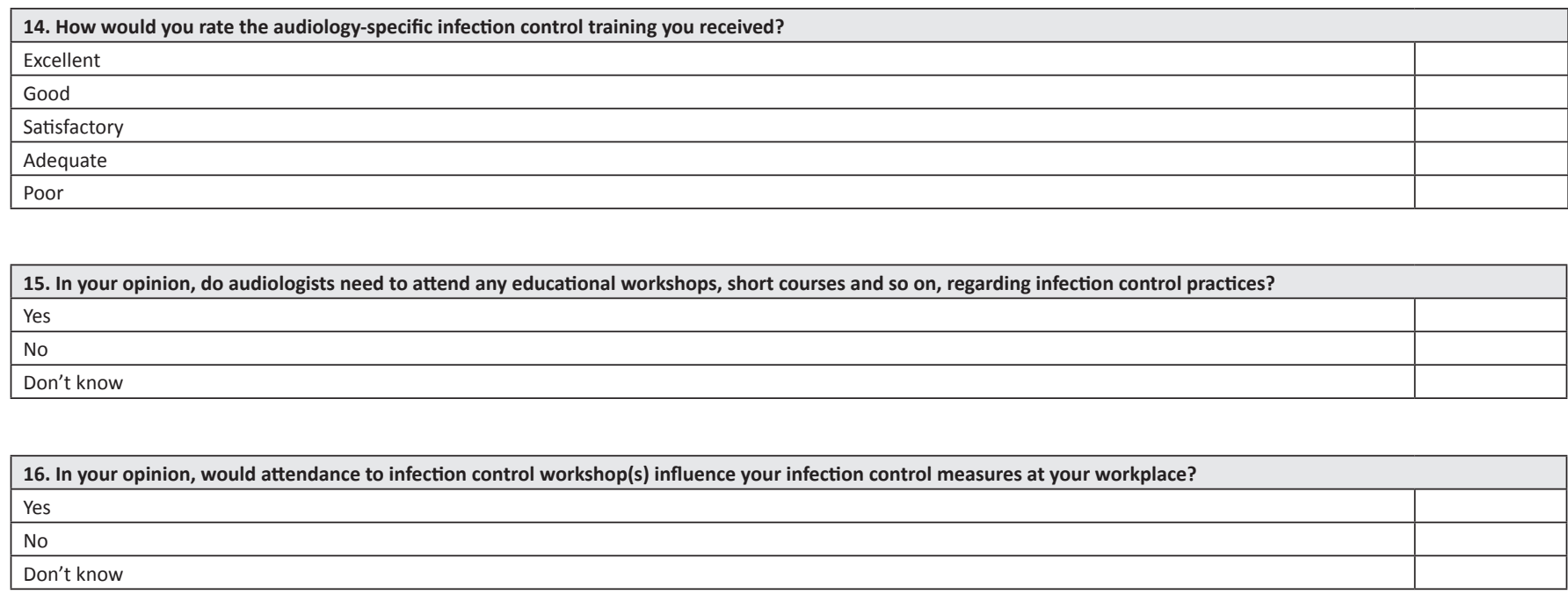

\begin{tabular}{|l|}
\hline 17. In your opinion, list content areas you feel should be included in infection prevention and control training for audiologists. \\
\hline \\
\hline \\
\hline
\end{tabular}

\section{Section C: Handwashing}

\begin{tabular}{|c|c|c|c|c|}
\hline \multicolumn{5}{|c|}{ 18. Do you follow the following procedures? (Please tick the option[s] that fit best) } \\
\hline & & Always & Sometimes & Never \\
\hline Q18 a) & Washing your hands & & & \\
\hline Q18 b) & Wearing gloves with every patient & & & \\
\hline Q18 c) & Wearing masks with patients with a communicable disease & & & \\
\hline Q18 d) & Correct medical waste disposal & & & \\
\hline Q18 e) & Sterilising equipment & & & \\
\hline Q18f) & Disinfecting equipment & & & \\
\hline
\end{tabular}


19. Do you have access to alcohol-based hand rub at your workplace?

Yes

No

Unaware or don't know

20. Do you have a sink with running water in your consultation area?

Yes

No

\section{(If you answered yes to the above question, please answer the question below)}

\begin{tabular}{|l|l|}
\hline 21. What is the distance of the sink in relation to your consultation area? \\
\hline$<50 \mathrm{~m}$ & \\
\hline $50-100 \mathrm{~m}$ & \\
\hline$>100 \mathrm{~m}$ & \\
\hline
\end{tabular}

\begin{tabular}{|l|l|l|}
\hline 22. In your opinion, should hands be washed ... ? (Please select those which apply to you) \\
\hline Q19 a) & Before each patient & \\
\hline Q19 b) & After each patient & \\
\hline Q19 c) & After cerumen management & \\
\hline Q19 d) & After earmould impression taking & \\
\hline Q19 e) & After use of the toilet & \\
\hline Q19 f) & After contact with bodily fluids & \\
\hline
\end{tabular}

23. Do you think adequate hand hygiene is an essential part of infection control?

Always

Sometimes

Never

Not applicable

If you selected 'sometimes' please explain when ...

24. Which of the following do you consider as adequate hand hygiene? (Please tick the option/s that apply)

\begin{tabular}{|l|l|}
\hline Q21 a) & Washing your hands after removal of gloves? \\
\hline Q21 b) & Washing your hands after cerumen management? \\
\hline Q21 c) & Washing your hands before contact with every individual patient? \\
\hline Q21 d) & Washing your hands after contact with each individual patient? \\
\hline
\end{tabular}

25. Do you wash your hands with ...?

Water

Water and soap

Hibitine solution

Liquid hand wash

Other:

\section{Section D: Personal protective measures}

(Please tick the option[s] that fit best)

\begin{tabular}{|l|l|}
\hline 26. Should audiologists receive vaccinations for hepatitis B? \\
\hline Yes & \\
\hline No & \\
\hline Unaware or don't know & \\
\hline
\end{tabular}

\begin{tabular}{|l|l|}
\hline 27. Do you think your workplace has a high exposure to communicable disease(s)? \\
\hline Yes & \\
\hline No & \\
\hline Unaware or don't know & \\
\hline
\end{tabular}


28. Do you think your workplace has adequate ventilation for those individuals who may have communicable diseases (e.g. TB)?

Yes

No

Unaware or don't know

29. In your opinion, should masks be available at your workplace?

Yes (always available)

Sometimes

No (never)

(If you answered 'yes' to the above question, please answer the question below)

30. In your opinion, when should masks be worn?

With every patient

Sometimes

Only when in contact with a person with a communicable disease (e.g. TB)

31. In your opinion, when should gloves be worn, during ... ? (Please tick the option that applies in each case)

\begin{tabular}{|c|c|c|c|c|}
\hline & & Always & Sometimes & Never \\
\hline Q31 a) & Otoscopy & & & \\
\hline Q31 b) & Immittance & & & \\
\hline Q31 c) & Cerumen management & & & \\
\hline Q31 d) & Evoked potentials & & & \\
\hline Q31 e) & Vestibular and balance testing & & & \\
\hline Q31 f) & Earmould impression taking & & & \\
\hline Q31 g) & Hearing aid fittings & & & \\
\hline
\end{tabular}

32. Have you sustained any injuries or infections at your workplace related to poor infection prevention and control measures? If so please explain ...

\section{Section E: Management of equipment and waste disposal}

(Please tick the option[s] that fit best)

\begin{tabular}{|l|l|l|}
\hline 33. In your opinion, on a daily basis, should the following instruments be disinfected and/or sterilised after use? (Please tick all the option/s that apply) \\
\hline Q33 a) & Otoscope specula & \\
\hline Q33 b) & Reusable auditory brainstem response (ABR) electrodes & \\
\hline Q33 c) & Reusable electronystagmography (ENG) electrodes & \\
\hline Q33 d) & Otolight & \\
\hline Q33 e) & ENG irrigator tip & \\
\hline Q33 f) & ENG specula & \\
\hline Q33 g) & Real-ear probe tips & \\
\hline Q33 h) & Headphones or insert earphones & \\
\hline Q33 i) & Immittance probe tip & Acrylic earmoulds used during hearing aid fitting \\
\hline Q33 j) & &
\end{tabular}

\begin{tabular}{|l|l|l|}
\hline 34. Which items do you think could most likely expose one to infectious diseases? \\
\hline Q34 a) & Otoscope specula & \\
\hline Q34 b) & Immittance probes & \\
\hline Q34 c) & Hearing aids & \\
\hline Q34 d) & Otoacoustic emission (OAE) probes & \\
\hline Q34 e) & Headphones and insert earphones & \\
\hline Q34 f) & Distraction toys & \\
\hline
\end{tabular}


35. In your opinion, how often should the following activities be conducted at your current workplace?

\begin{tabular}{|l|l|l|l|l|}
\hline \multicolumn{2}{|l|}{ 35. In your opinion, how often should the following activities be conducted at your current workplace? } \\
\hline \multicolumn{2}{|l|}{ Q35 a) } & Sterilise equipment & \multicolumn{1}{|c|}{ Sometimes } & N/A \\
\hline Q35 b) & Clean the audiometer & & & \\
\hline Q35 c) & $\begin{array}{l}\text { Disinfect headphones used during Pure } \\
\text { Tone Audiometry (PTA) }\end{array}$ & & & \\
\hline Q35 d) & Sterilise otoscope specula & & & \\
\hline Q35 e) & Sterilise probe tips used & & & \\
\hline
\end{tabular}

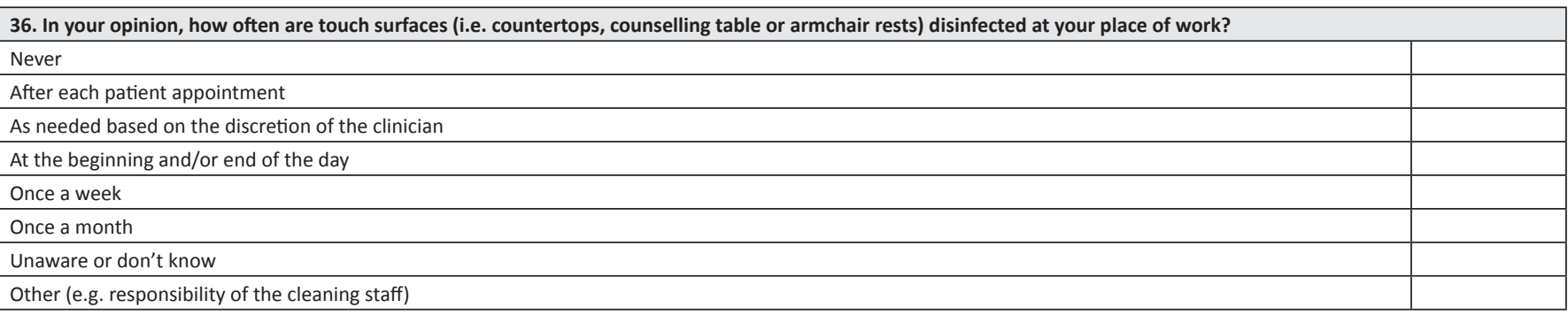

\begin{tabular}{|l|l|}
\hline 37. In your opinion, how often should toys used during paediatric hearing assessments be disinfected? \\
\hline Never & \\
\hline After each patient appointment & \\
\hline As needed based on the discretion of the clinician & \\
\hline At the beginning and/or end of the day & \\
\hline Once a week & \\
\hline Once a month & \\
\hline Not applicable & \\
\hline Don't see paediatric patients & \\
\hline
\end{tabular}

\begin{tabular}{|l|l|l|l|l|}
\hline 38. Are there medical waste disposal bins available in your current work setting? & \multicolumn{1}{|c|}{ Yes } & No & \\
\hline & & & \\
\hline Q38 a) & Red (infectious substances, i.e. gloves, swabs) & & & \\
\hline Q38 b) & Yellow ('sharps', i.e. needles, syringes) & & & \\
\hline Q38 c) & Green (pharmaceuticals, i.e. expired medication) & & \\
\hline
\end{tabular}

\begin{tabular}{|l|l|}
\hline 39. In your opinion, should medical waste be put in the same dustbin as general wastes? \\
\hline Yes & \\
\hline No & \\
\hline Unaware or don't know & \\
\hline
\end{tabular}

\begin{tabular}{|l|l|}
\hline 40. In your opinion, should hearing aid batteries be disposed of separate from other wastes? \\
\hline Yes & \\
\hline No & \\
\hline Unaware or don't know & \\
\hline
\end{tabular}

Thank you for your time and participation. 